\title{
Test Study on Cube Compressive Strength of Recycled Lightweight Aggregate Concrete
}

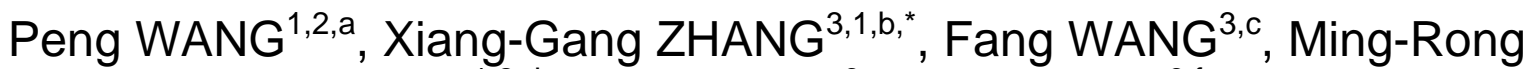 \\ DENG ${ }^{1,2, d}$, Wen-Bo QIN ${ }^{3, e}$ and Qi TIAN ${ }^{3, f}$ \\ ${ }^{1}$ Guangxi Key Lab of Road structure and materials, Nanning, China \\ ${ }^{2}$ Guangxi Transportation Research Institute, Nanning, China \\ ${ }^{3}$ School of Civil Engineering, Henan Polytechnic University, Jiaozuo, China \\ a176356818@qq.com, bxgzhang@hpu.edu.cn, c418824997@qq.com, d41345097@qq.com, \\ e302583907@qq.com, ${ }^{\mathrm{f}}$ 1291238829@qq.com
}

*Corresponding author

Keywords: Recycled lightweight aggregate concrete, Cube compressive strength, Replacement rate of recycled lightweight coarse aggregate

\begin{abstract}
In order to study cube compressive strength of recycled lightweight aggregate concrete, with the change parameters of replacement rate of recycled lightweight coarse aggregate, 15 standard cube test blocks were designed and produced to carry out compressive strength test. The failure process and failure mode of test blocks were recorded; cube compressive strength of test blocks were measured, based on the principle of least square method, the relation curves between cube compressive strength and replacement rate were all analyzed and fitted, the influence change parameters made on cube compressive strength was discussed. It is shown that splitting failure occurs in the test blocks of recycled lightweight aggregate concrete at last; the relations between cube compressive strength and replacement rate are all linear functions; cube compressive strength of recycled lightweight aggregate concrete increases as replacement rate of recycled lightweight coarse aggregate decreases.
\end{abstract}

\section{Introduction}

With the rapid development of urbanization process in China, a lot of construction waste is generated by the demolition and renovation of existing buildings and new construction [1 2]. According to statistics [3], at present, construction waste has reached $30 \%$ to $40 \%$ of municipal waste in China, of which $50 \%$ to $60 \%$ was waste concrete. Landfilling simply or duming openly construction waste is a waste of limited land and resources, the natural environment will be polluted. Moreover, For a long time, due to the source of aggregate of sand and stone is extensive, and the cost of one is inexpensive, so aggregate is mined arbitrarily, and natural aggregate has already depleted in some areas. Effectively dealing with construction waste and shortage of natural aggregate has important significance for the sustainable development of the construction industry [4 5].

At present, technology of recycled aggregate concrete has become an effective way of construction waste resource utilization [6]. However, The sources of recycled coarse aggregate in RAC is wide, in previous studies[7 9], recycled coarse aggregate was mostly from ordinary concrete, while the studies on source from the demolished lightweight aggregate concrete structures (such as long-span bridges, high-rise building, road pavement, et al) are little. As a construction waste source, through the RAC technology, the purpose of building waste recycling for lightweight aggregate concrete can be achieved. And after the recycled light coarse aggregate is joined, ordinary concrete not only inherits the advantages of small weight of lightweight aggregate concrete, excellent thermal performance and good seismic performance, but also improves the mechanical property defect such as low strength of lightweight aggregate concrete and bad elastic modulus and so on. 
Based on the compressive test of 15 recycled lightweight aggregate concrete block, the uniaxial compressive strength and influence factors of recycled lightweight aggregate concrete were in-depth analyzed to enrich the research content of RAC structure, so the reference and mirror for further research and application of recycled lightweight aggregate concrete were provided.

\section{Test overview}

\section{Test Materials}

The raw materials including cement, natural coarse aggregate, recycled lightweight coarse aggregate, river sand and water were used to prepare recycled lightweight aggregate concrete. The P.O 42.5 cement produced by the Jiaozuo limited company of sturdy cement was adopted, the continuous grade gravel was selected as natural coarse aggregate as shown in Fig.1(a), recycled lightweight coarse aggregate shown in Fig.1(b) was derived after the tested cube blocks of lightweight aggregate concrete in structure hall of Henan Polytechnic University was crushed, screened, washed and dried, the destroyed test blocks were made up of lightweight aggregate concrete of LC25 and LC20, the crushed lightweight aggregate concrete blocks were uniformly mixed in a 1:1 volume ratio to produce the recycled light coarse aggregate, grain composition of recycled lightweight coarse aggregate kept same with one of natural coarse aggregate, the basic physical property indexes of the two coarse aggregates were shown in Tab.1. It was shown that bulk density and apparent density of recycled lightweight coarse aggregate are much smaller than ones of natural coarse aggregate, and absorption of recycled lightweight coarse aggregate was up to about $9.5 \%$, higher than ones of recycled ordinary coarse aggregate, this is because not only a large number of cement mortar is adhered on the surface of recycled lightweight coarse aggregate, but also the interior of recycled lightweight coarse aggregate is made up of porous lightweight aggregate with high water absorption. Middle sand was selected as river sand, tap water was selected as mixing and conservation water.

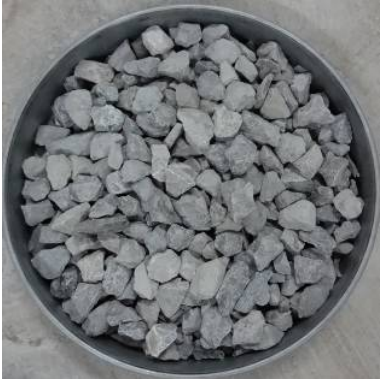

(a) Natural coarse aggregate

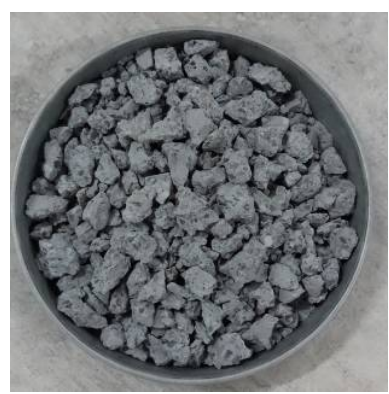

(b) Recycled lightweight coarse aggregate

Fig.1 Coarse aggregate

Tab.1 The basic physical property indexes of natural coarse aggregate and recycled lightweight coarse aggregate

\begin{tabular}{|c|c|c|c|c|c|}
\hline Aggregate Category & $\begin{array}{l}\text { Grain size } \\
/ \mathrm{mm}\end{array}$ & $\begin{array}{l}\text { Bulk density } \\
/\left(\mathrm{kg} / \mathrm{m}^{3}\right)\end{array}$ & $\begin{array}{l}\text { Apparent } \\
\text { density } /\left(\mathrm{kg} / \mathrm{m}^{3}\right)\end{array}$ & $\begin{array}{l}\text { Water } \\
\text { absorption /\% }\end{array}$ & $\begin{array}{l}\text { Voidage } \\
/ \%\end{array}$ \\
\hline $\begin{array}{l}\text { Natural } \\
\text { aggregate }\end{array}$ & $5 \sim 31.5$ & 1481 & 2500 & 0.62 & 40.76 \\
\hline $\begin{array}{l}\text { Recycled lightweight } \\
\text { coarse aggregate }\end{array}$ & $5 \sim 31.5$ & 776 & 1389 & 9.46 & 44.13 \\
\hline
\end{tabular}

\section{Mix Proportion}

Replacement rate of recycled lightweight coarse aggregate is the bulk volume proportion between recycled lightweight coarse aggregate and all the coarse aggregate. Replacement rates of $0 \%, 25 \%$, $50 \%, 75 \%$ and $100 \%$ were designed in this test, mix proportion of recycled lightweight aggregate 
concrete was designed by the way of bulk volume. Under different replacement rates, $1 \mathrm{~m}^{3}$ quality mix proportion of LC20 recycled lightweight aggregate concrete was shown in Tab.2, in which, additional water is considered because of absorption of recycled lightweight coarse aggregate, effective water-cement ratio was the quality proportion between net water and cement.

Tab.2 Quality mix proportion of recycled lightweight aggregate concrete

\begin{tabular}{llllllll}
\hline $\begin{array}{l}\text { Replacement } \\
\text { rate }\end{array}$ & Cement/kg & $\begin{array}{l}\text { Natural } \\
\text { coarse } \\
\text { aggregate/kg }\end{array}$ & $\begin{array}{l}\text { Recycled } \\
\text { lightweight } \\
\text { coarse } \\
\text { aggregate/kg }\end{array}$ & Sand/kg & $\begin{array}{l}\text { Net duty } \\
\text { of } \\
\text { water/kg }\end{array}$ & $\begin{array}{l}\text { Additional } \\
\text { water/kg }\end{array}$ & $\begin{array}{l}\text { Effective } \\
\text { water to } \\
\text { binder } \\
\text { ratio }\end{array}$ \\
\hline $0 \%$ & 440.00 & 1066.32 & 0.00 & 634.08 & 208.00 & 0.00 & 0.47 \\
$25 \%$ & 440.00 & 799.74 & 139.68 & 634.08 & 208.00 & 13.21 & 0.47 \\
$50 \%$ & 440.00 & 533.16 & 279.36 & 634.08 & 208.00 & 26.43 & 0.47 \\
$75 \%$ & 440.00 & 266.58 & 419.04 & 634.08 & 208.00 & 39.64 & 0.47 \\
$100 \%$ & 440.00 & 0.00 & 558.72 & 634.08 & 208.00 & 52.85 & 0.47 \\
\hline
\end{tabular}

\section{Production and Loading of Test Block}

Standard design of $150 \mathrm{~mm} \times 150 \mathrm{~mm} \times 150 \mathrm{~mm}$ size for test block was used. To ensure the smoothness of the surface of test block, steel tryouts for all test blocks were used. According to "Test Method Standards for Ordinary Concrete Mixture Performance”(GB/T50080-2002), molding operation for recycled lightweight aggregate concrete was carried out, form removal was made after curing for $24 \mathrm{~h}$, then test blocks were cured for $28 \mathrm{~d}$ at the standard curing chamber of which temperature was 20

${ }^{\circ} \mathrm{C}$, relative humidity was $90 \%$.

Based on national standards "Ordinary Concrete Mechanical Performance Test Method" (GB50081-2002), Loading was carried out on the pressure testing machine of SYE-2000, Loading rate was $9 \mathrm{kN} / \mathrm{s}$, the maximum range used in this test was $2000 \mathrm{kN}$.

\section{Test results and Analysis}

\section{Failure Process and Mode}

Failure processes of test blocks are similar to ones of recycled lightweight aggregate concrete. At the early loading, there were no visible cracks on the surfaces of test blocks. With load increasing, stress and strain in the test block increased gradually. When the load was closed to the destruction, small and vertical cracks appeared at the center of test block height. With loading continuing, cracks expanded and extended gradually towards the upper and the lower parts, then the main crack was formed, splitting failure appeared at the last. Failure modes of partial test blocks were shown in Fig.2.
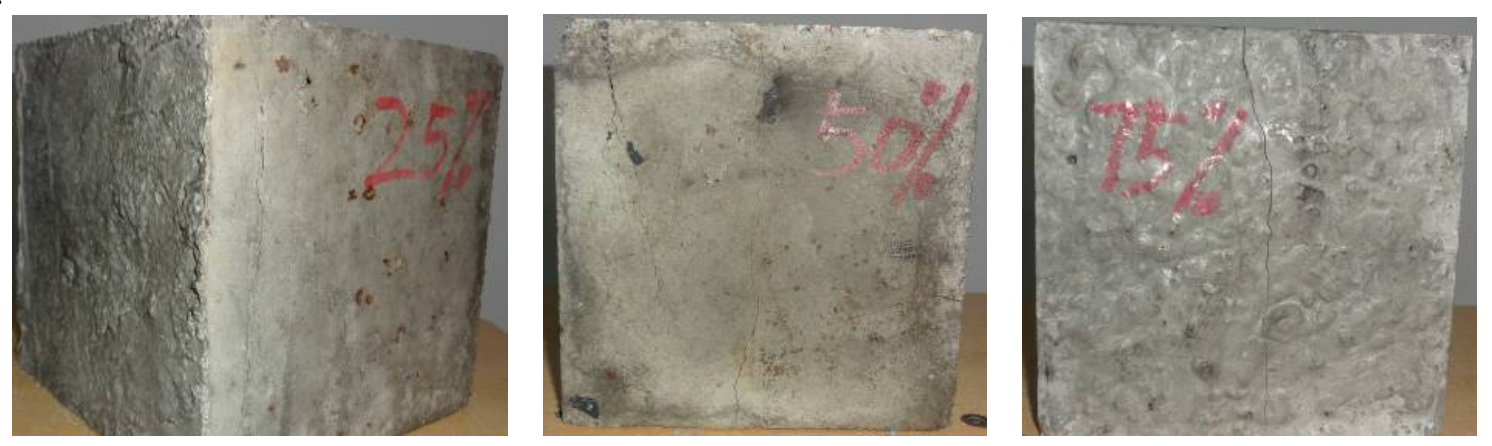

Fig.2 Failure modes

It is shown that failure modes of test blocks of recycled lightweight aggregate concrete are not consistent to the pyramidal failure modes of ordinary concrete, this is because recycled lightweight aggregate was porous and brittle, after being joined into ordinary concrete, the apparent characteristics and deformation modulus of concrete will be changed, then the friction on the 
pressure receiving surface between the upper pressure plate and the lower one in the pressure testing machine weakens greatly, so the binding for the lateral deformation of the pressure receiving surface is reduced, splitting failure along the direction which was parallel to the force appears in the test blocks.

\section{Cube Compressive Strength}

Destroy load of all the test blocks could be measured, bearing area of test block was known, based on dispose approach of test data in "Ordinary Concrete Mechanical Performance Test Method”(GB50081- 2002), cube compressive strengths of recycled lightweight aggregate concrete test blocks under different replacement rates could be calculated, as shown in Tab.3.

It is shown that cube compressive strengths of recycled lightweight aggregate concrete test blocks under different replacement rates all reach the requirements of design strength grades, and good regularity is exhibited, as shown in Fig.3.

Tab.3 Cube compressive strength of recycled lightweight aggregate concrete

\begin{tabular}{llllll}
\hline $\begin{array}{l}\text { Replacement } \\
\text { rate }\end{array}$ & $0 \%$ & $25 \%$ & $50 \%$ & $75 \%$ & $100 \%$ \\
\hline $\begin{array}{l}\text { Cube } \\
\begin{array}{l}\text { compressive } \\
\text { strength/MPa }\end{array}\end{array}$ & 37.62 & 31.82 & 27.72 & 26.68 & 20.57 \\
\hline
\end{tabular}

It is seen in Fig.5 cube compressive strength of recycled lightweight aggregate concrete and replacement rate show a linear function relationship, the mathematical expression is:

$y=a x+b$

In which, $a, b$ are the control parameters, which can be fitted by least squares method based on measured test data. So $a$ is taken as $-15.696, b$ is taken as 36.730 , the fitting precision is 0.9476 .

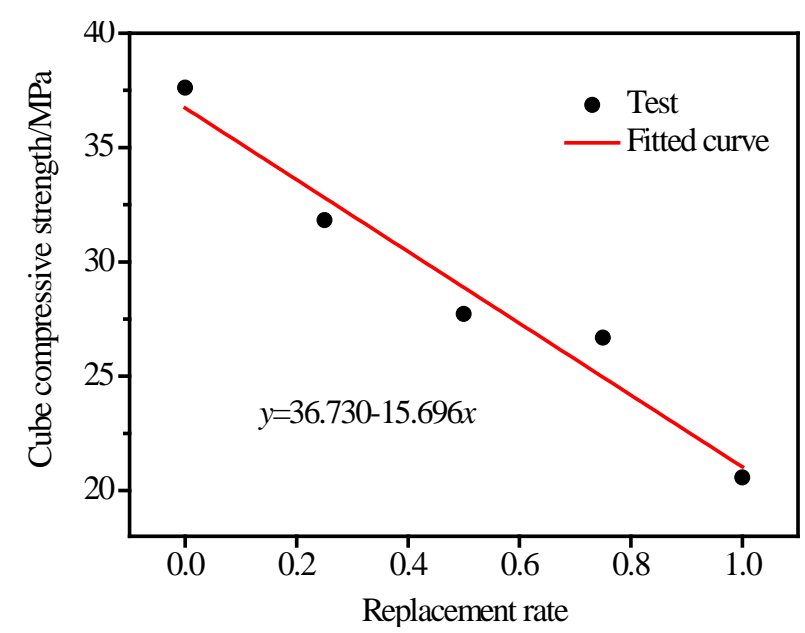

Fig.3 Relation curve between cube

compressive strength and replacement rate

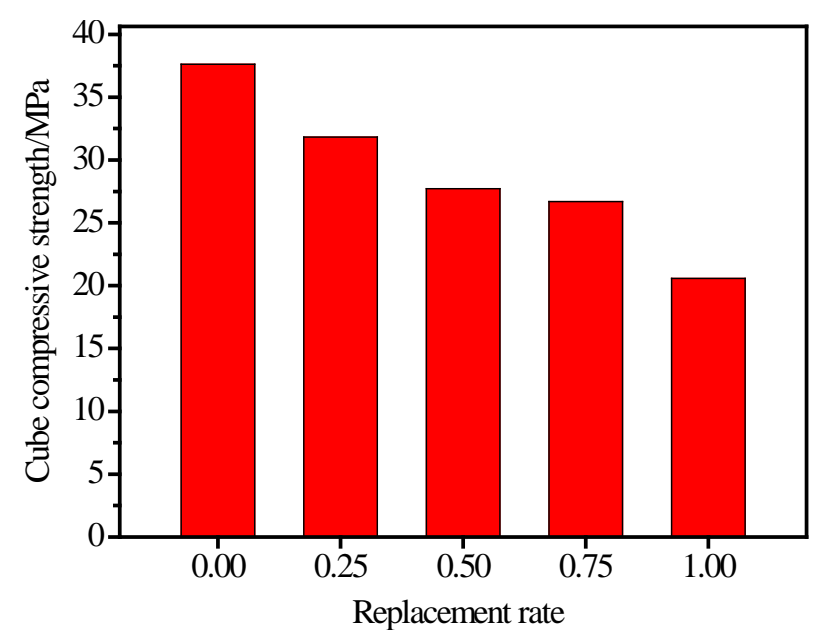

Fig.4 Cube compressive strength

under different replacement rate

\section{Influence Factors Analysis of Replacement Rate}

Cube compressive strengths of recycled lightweight aggregate concrete test blocks under different replacement rates are shown in Fig.4. It was shown that with replacement rate decreasing, Cube compressive strengths of recycled lightweight aggregate concrete increases gradually, this is because the coarse aggregate strength of lightweight aggregate concrete is less than one of the cement mortar, resulting in the destruction of coarse aggregate in lightweight aggregate concrete, that means coarse aggregate strength is the deciding factor for the strength of lightweight aggregate concrete. For recycled lightweight aggregate concrete, due to the presence of natural stones, 
strength of coarse aggregate made up of recycled lightweight coarse aggregate and stones will be improved to some extent, the higher the content of natural stone, the greater the magnitude of strength improvement. When the replacement rate changes from $100 \%$ to $0 \%$, increase rate of cube compressive strength were $29.70 \%, 3.90 \%, 14.79 \%$ and $18.23 \%$ respectively.

\section{Conclusions}

In this paper, compressive strength test and analysis were carried out on 15 standard cube test blocks of recycled lightweight coarse aggregate under different replacement rates, the main conclusions are as follows:

(1) For recycled lightweight aggregate concrete, splitting failure appeared at the last, failure modes of test blocks of recycled lightweight aggregate concrete are not consistent to the pyramidal failure modes of ordinary concrete.

(2) With replacement rate of recycled light coarse aggregate reducing, cube compressive strength of recycled lightweight aggregate concrete increases, the linear function relationship presents between replacement rate of recycled light coarse aggregate and cube compressive strength of recycled lightweight aggregate concrete.

\section{References}

[1] CAO Wanlin, CHENG Juan, ZHANG Yongbo, et al. Experiment of seismic behavior of low-rise recycled aggregate concrete shear wall with insulation blocks and single layer of reinforcement[J]. Journal of Building Structures, 2015, 36(1): 51-58. (in Chinese)

[2] ZHANG Xianggang, CHEN Zongping, XUE Jianyang. Physical and Mechanical Performance of Recycled Aggregate Concrete[J]. Bulletin of the Chinese Ceramic Society, 2015, 34(6): 1684 1689. (in Chinese)

[3] ZHAO Jun, LIU Qiuxia, LIN Liqing, et al. Evolution and comparison of construction waste of large cities in China[J]. Journal of Central South University (Science and Technology), 2013, 44(3): 1297-1304. (in Chinese)

[4] LIU Shuhua, YAN Peiyu. Mechanical properties of recycled aggregate concret[J]. Engineering Journal of Wuhan University, 2010, 43(1): 85-101. (in Chinese)

[5] Monalisa B, Bhattacharyya S K , Minocha A K ,et al. Recycled aggregate from C\&D waste \& its use in concrete $-\mathrm{A}$ breakthrough towards sustainability in construction sector: A review[J]. Construction and Building Materials, 2014, 68: 501-516.

[6] ZHANG S P, ZONG L. Properties of concrete made with recycled coarse aggregate from waste brick[J]. Environmental Progress \& Sustainable Energy, 2014, 33(4): 1283-1289.

[7] ZHANG Yamei, Qin honggen, Sunwei, et al. Primary investigation on mix proportion design of recycled aggregate concrete[J]. China Concrete and Cement Products, 2002, 12(1): 7-9.

[8] LI Qiuyi, LI Yunxia, ZHU Chongji, et al. Strengthening technique of recycled concrete aggregate[J]. Concrete, 2006, 1: 74-77. (in Chinese)

[9] WANG Xingguo, LI Li, WANG Wenhua. Application prospect and characteristic of recycled concrete performance[J]. Journal of Henan Polytechnic University(Natural Science), 2012, 31(1): 95-99, 108. (in Chinese) 